\title{
Avaliação de um equipamento protótipo para tratamento de águas cinzas com fins não potáveis
}

\author{
Lueny Santos da Costa'; Luísa Rodrigues de Oliveira'; Rodrigo Martinez Castro'; Martha \\ Nascimento Castro'; Luiz Felipe Ordones Almeida'; Erick William Viais Carvalho ${ }^{l}$
}

luisa_rodriguesl3@hotmail.com

1. Pontifícia Universidade Católica de Goiás - Goiás, Brasil

Histórico do Artigo:

Recebido em: 14 de março de 2018 Aceito em: 06 de junho de 2018 Publicado em: 28 de dezembro de 2018

Resumo: Devido possuir disponibilidade por meio de um ciclo natural, acreditava-se que a água seria um recurso natural inesgotável, no entanto, o tempo necessário para se tornar tal recurso potável novamente é longo. 0 Brasil já sofre com escassez de água, mesmo estando localizado em um continente com grande volume de reservas hídricas. A constatação desses dados permite perceber não só a necessidade de se criar, mas também de se aplicar efetivamente novas tecnologias, que ajudem a racionalizar o uso de água potável. A reutilização de águas cinzas se apresenta como uma alternativa nesse processo de economia e preservação, trazendo benefícios ecológicos e sociais. 0 presente artigo abordará as possíveis utilizações das águas submetidas à reciclagem e a importância de se conhecer e incentivar estudos na área de sustentabilidade. Será apresentada a construção do protótipo criado, composto por tratamento físico, químico e biológico, em que sua eficiência foi atestada por meio de análises em amostras e por comparações de resultados com parâmetros nacionais de qualidade. Alguns dos parâmetros analisados durante o estudo obtiveram uma redução expressiva, por exemplo: turbidez - 91\% e sólidos dissolvidos totais - 71\%, para a terceira coleta. Considerando os resultados obtidos das análises, para 0 tratamento da água cinza, seus usos para fins não potáveis devem ser estimulados.

Palavras-chave: Sustentabilidade, águas cinzas, águas de reúso, IQA Seachem Purigen

\section{Evaluation of greywater treatment prototype equipment for non-potable purposes}

\begin{abstract}
Due to availability through a natural cycle, it was believed that water would be an inexhaustible natural resource, however, a long time is required to become a drinkable resource again. Brazil already suffers with water shortages, even though it is located on the continent with large volume of water reserves. Data analysis and verification enforce the need to create, but also to effectively apply new technologies that help to rationalize the use of drinking water. The reuse of gray water presents itself as an alternative process of economy and preservation, bringing ecological and social benefits. This article will address the possible uses of greywater submitted to a specific recycling system, and the importance of knowing and encouraging studies in the sustainability field. It will be presented a filtering prototype development, composed by physical, chemical and biological treatment, in which its efficiency was attested by means of analyzes in samples and by results comparisons with Brazilian national quality parameters. Some of the analyzed parameters during the study obtained a expressive reduction, for an example: $91 \%$ reduction on turbidity and $71 \%$ on total dissolved solids, for the third collection already. Considering the results obtained from greywater analyses, their uses for non-potable purposes should be stimulated.
\end{abstract}

Keywords: Sustainability, gray water, water reuse, IQA, Seachem Purigen. 


\section{Evaluación de un equipo prototipo de tratamiento de aguas grises para fines no potable}

Resumen: Debido a la disponibilidad por medio de un ciclo natural, se creía que el agua sería un recurso natural inagotable, sin embargo, el tempo necesario para convertirse en tal recurso potable de nuevo es largo. Brasil ya sufre com escasez de agua, aun estando localizado em un continente com gran volumen de reservas hídricas. La constatación de estos datos permite percibir no sólo la necesidad de crearse, sino también de aplicar efectivamente nuevas tecnologías que ayuden a racionalizar el uso de agua potable. La reutilización de aguas grises se presenta como un alternativo proceso de economía y preservación, aportando beneficios ecológicos y sociales. El presente artículo abordará los posibles usos de las aguas sometidas al reciclaje y la importancia de conocer y incentivar estúdios sobre la sostenibilidad. Se presentará la construcción del protótipo creado, compuesto por tratamiento físico, químico y biológico, en que sueficiencia fue atestada por medio de análisis em muestras y por comparaciones de resultados com parâmetros nacionales de calidad. Algunos de losparámetros analizados durante el estúdio obtuvieron una reducción expresiva, por ejemplo: turbidez - 91\% y sólidos disueltos totales - 71\%, para la terceira colecta. Considerando los resultados obtenidos de los análisis, para el tratamento del agua gris, sus usos para fines no potables deben ser estimulados.

\section{INTRODUÇÃO}

A água é um recurso estratégico para a humanidade, pois mantém a vida no planeta Terra, sustenta a biodiversidade, a produção de alimentos e suporta todos os ciclos naturais, e tem, portanto, importância ecológica, econômica e social. A humanidade dependeu, e sempre dependerá da água para sua sobrevivência econômica e biológica, e para o desenvolvimento financeiro e cultural. (GALIZIA E MATSUMURA, 2009).

Por possuir um ciclo natural, acreditava-se que a água nunca acabaria, porém sua renovação leva tempo e o acesso a ela está ficando cada dia mais desafiador. A maior parte da água presente no planeta é salgada, proveniente dos oceanos, e as águas doces englobam apenas $2,4 \%$ do total, sendo que aproximadamente $70 \%$ provem de geleiras e a quantidade presente em lagos e rios é pequena, $0,02 \%$, sendo boa parte poluída, diminuindo ainda mais a porcentagem de água disponível para o consumo humano (FREITAS, 2016; GLEICK,1996).

É de fundamental relevância o desenvolvimento de tecnologias e soluções alternativas, uma vez que o aumento populacional faz com que a demanda pelos recursos hídricos aumente dia após dia. Mesmo que a água fosse um recurso amplamente renovável, o uso irresponsável pode comprometer a sua disponibilidade quantitativa e qualitativa. Nesse contexto, o incentivo ao seu uso racional é uma forma de prevenir a escassez (VIEIRA et al., 2006).

Observa-se uma crescente importância do tema de reuso de águas cinzas, o qual ganhou visibilidade após as crises hídricas observadas desde 2014. Essa temática, a princípio, bastante restritiva à realidade da região Nordeste do país, apresenta-se hoje, aplicável a todo 
o território nacional, independente de nível de desenvolvimento econômico. A escassez do recurso "água” associada ao aumento da demanda por água potável, responde por essa mudança de cenário e impulsiona na sociedade, discussões sobre a importância do reaproveitamento consciente desse recurso: o que antes seria descartado, mostra-se hoje como matéria de reutilização para fins específicos. (SINDUSCON, 2005).

Segundo Muller (2015), a água cinza é aquela que já foi utilizada no chuveiro e nas torneiras de lavagem de mãos, por exemplo, e que após o primeiro uso, normalmente segue pela tubulação de descarte, coleta e tratamento. Contém em sua maior parte material orgânico, tais como restos de pele e fios de cabelo, precisando de tratamento biológico, antes de ser filtrada. Após tratadas essas águas podem ser usadas em vasos sanitários, rega de plantas, limpeza de pisos, lavagem de carros, reposição de espelhos d'água, sistemas de arcondicionado e até em algumas atividades da construção civil.

A reutilização de águas cinzas além de acarretar em benefício ecológico é uma alternativa para reduzir os gastos domésticos, vistos os reajustes nas tarifas de água. A adoção dessa tecnologia tem atraído bastante atenção do mercado imobiliário, porém ela ainda esbarra na desconfiança dos moradores que têm receio em utilizá-la, aliado a isso a falta de uma normatização específica para esse sistema incrementa a dificuldade de adoção desse uso. Em relação à desconfiança sobre a qualidade da água, existem tecnologias avançadas, tais como, membranas e filtros sofisticados que permitem alcançar melhor qualidade da água que ajudam a vencer esta resistência da população, no entanto é preciso criar normas que exijam um padrão de qualidade mínima a ser seguido. (MULLER, 2015).

A escolha do sistema alternativo de água deve considerar não só os custos da implantação, mas também aqueles relativos à descontinuidade de fornecimento. A Associação Brasileira de Normas Técnicas, ainda não possui normas que estabelecem os requisitos necessários para a implantação de um sistema de reuso de água, porém existem exigências mínimas para o uso de água não potável, tais como ausência de mau-cheiro, não ser abrasiva, não manchar superfícies ou deteriorar metais, não ser turva, não propiciar infeç̧ões ou contaminações e etc. (SINDUSCON, 2005).

Barreto (2008) realizou uma pesquisa sobre o consumo residencial e usos finais da água em residências da cidade de São Paulo e percebeu uma relação crescente entre a renda e o consumo de água. Na pesquisa notou-se que o chuveiro foi a unidade que mais consumiu água, com $13,9 \%$ do total, seguido pela pia da cozinha com $12 \%$. Ao todo, a porcentagem de águas cinzas geradas foi de aproximadamente $63 \%$. Sendo assim, com a reutilização de 
recursos hídricos é possível diminuir o consumo de água tratada nas residências, ajudando não só ao país e às famílias, mas também ao planeta.

A preocupação e a necessidade de medidas para preservação de água já foram detectadas pelos governantes do nosso país, e um exemplo disso foi o da Prefeitura do município de Niterói, no Estado do Rio de Janeiro, que sancionou a Lei $n^{\circ} 2856$ no ano de 2011, estendendo a Lei $\mathrm{n}^{0} 2630$ de 2009, que procura incentivar 0 armazenamento e 0 reaproveitamento de águas pluviais. Essa nova lei estipula a instalação de sistemas de coletas e reutilização de águas cinzas presentes nas novas edificações que possuam um consumo superior a vinte metros cúbicos de água por dia. Outra atitude tomada visando o maior conhecimento dessa técnica foi o lançamento do "Manual para aproveitamento emergencial de águas cinzas do banho e da máquina de lavar” pelo IPT (Instituto de Pesquisas Tecnológicas), o qual apresenta os usos e cuidados ao utilizar esse tipo de água e também mostra como coletar e armazená-la.

0 objetivo principal deste artigo é mostrar a importância de utilizar métodos sustentáveis nas construções visando o reaproveitamento das águas cinzas com a finalidade de economizar água potável para fins não potáveis, testando a qualidade destas amostras coletadas após processamento por um sistema de tratamento, com etapas física, química e biológica, analisando em última instância, a eficiência do protótipo utilizado.

\section{MATERIAL E MÉTODOS}

0 experimento foi desenvolvido entre agosto e novembro de 2016 (quatro meses), durante as atividades acadêmicas de conclusão de curso dos autores e de iniciação científica dos co-autores, e foi realizado junto aos Laboratórios de Engenharia da Pontifícia Universidade Católica de Goiás, na cidade de Goiânia/G0, Lat. 1640'43.64"S, Long. $49^{\circ} 14^{4} 45.24$ "0, exceto pela análise de coliforme termotolerantes, que foi realizada em laboratório privado (Conágua Ambiental - Goiânia/G0). Todas as análises foram realizadas em ambiente climatizado controlado, com temperaturas próximas a $24^{\circ} \mathrm{C}$, e umidade relativa do ar aos $45 \%$ médios.

0 trabalho partiu da configuração e montagem de um equipamento protótipo de filtragem, que foi elaborado baseado em tratamento misto, composto por processo de filtragem física e química, e um tratamento biológico anaeróbico adicional (Figura 1). 


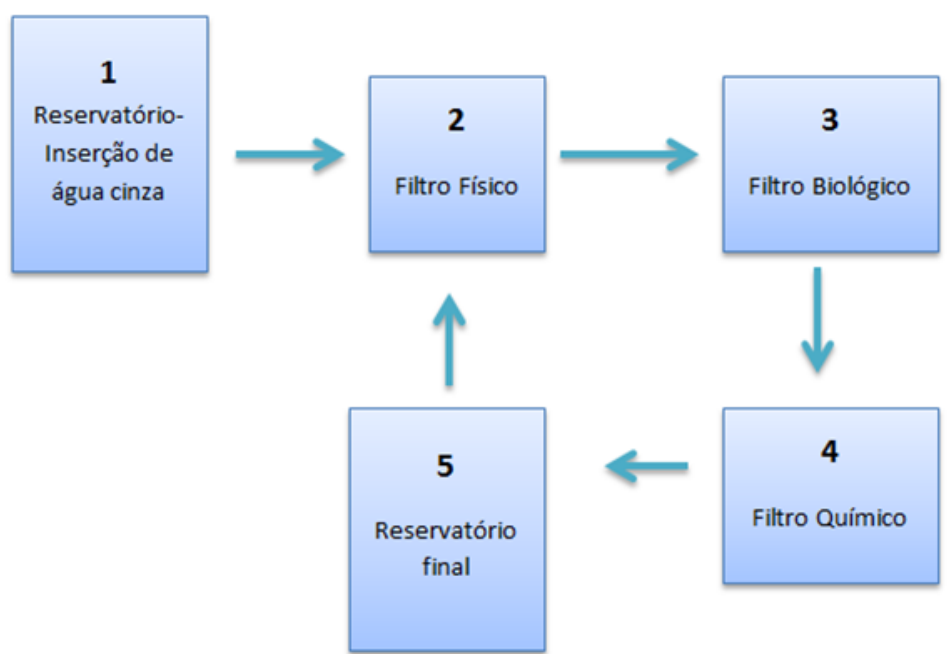

Figura 1. Representação esquemática do protótipo. Fonte: Autores, 2016.

0 sistema foi desenvolvido utilizando cinco recipientes (cubos retangulares) de vidro, construídos especialmente para esse protótipo (Figura 2), com volumes totais de 43 litros nos recipientes de filtragem (numerados em 2, 3 e 4 na Figura 1) e de 65 litros nos de armazenamento (itens 1 e 5 da Figura 1). Os recipientes de número um e cinco eram maiores que os outros e serviram como reservatórios inicial e final respectivamente, sendo que um deles recebia água cinza previamente coletada e o outro armazenava água após a filtragem. 0 reservatório de inserção de água cinza $\left(n^{0} 1\right.$ Figura 1), iniciava o tratamento físico através da passagem do efluente por um filtro simples de areia, com vazão reduzida, permitindo que a água ficasse em contato com o material filtrante por maior tempo.

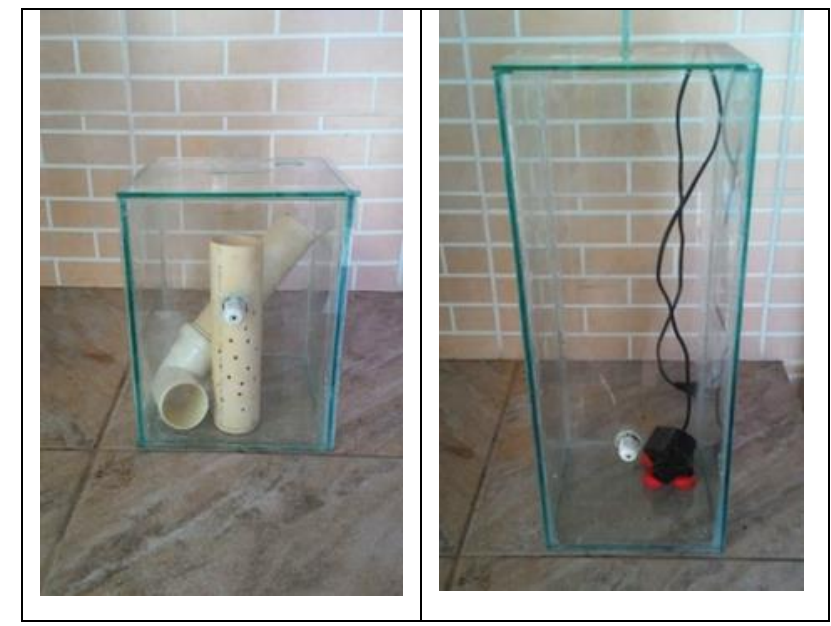

Figura 2. Recipientes construídos para o protótipo.

Fonte: Autores, 2016. 
0 segundo recipiente ( $n^{0} 2$ Figura 1) tinha a função de concluir a filtragem física através da passagem da água por uma manta sintética acrílica, composta de copolímero de poliéster acrílico, que possui pequenas fibras capazes de reter partículas maiores que $100 \mu$.

A terceira câmara de filtragem ( $n^{0} 3$ Figura 1) tinha a função de condicionar um ambiente propício para a colonização de bactérias, contendo pedras vulcânicas e partículas de materiais cerâmicos, que por sua porosidade, tem a capacidade de formar nichos de desenvolvimento para tais microrganismos. A colônia de bactérias foi artificialmente inserida, utilizando-se de solução concentrada de microorganismos (Special Blend®)- Fabricado pela Reef Safe). Esta etapa tem como objetivo proporcionar uma célula de filtragem para crescimento de colônia de microorganismos que vão consumir e remover a matéria orgânica da água.

A quarta etapa do sistema (recipiente $n^{0} 4$ Figura 1) estava abastecida por um polímero sintético macro poroso (Purigen $®$ - Fabricado pela Seachem), que tem alta capacidade de remoção orgânica, além de promover reações de retirada química parcial de poluentes como metais e químicos solúveis. Este polímero é formado por micro pellets e possui a característica de mudar de cor à medida que sua capacidade de filtragem é utilizada, ou seja, torna-se escuro quanto mais "sujo", sendo então regenerado ao estado natural por tratamento com hipoclorito de sódio a $60 \%$ v.v., realizado apenas entre as trocas das baterias de filtragem. Foram utilizados $100 \mathrm{ml}$ de Purigen®, suficientes para o tratamento de até 400 litros de água. 0 produto é desenvolvido para remoção de impurezas para águas de sustentação de vida animal (aquários) e um dos objetivos do protótipo era testar sua eficiência em tratamento de água cinza.

0 último recipiente do sistema $\left(n^{0} 5\right.$ Figura 1$)$ era um reservatório com função de armazenar a água tratada, sendo que neste foram coletadas as amostras para a realização dos testes, e, para reiniciar o sistema de tratamento, através de um pequeno dispositivo de bombeamento, possibilitando que a água retornasse para o segundo recipiente do protótipo, permanecendo num ciclo de filtragem separado da água de início (o que motiva a reinserção no reservatório de $n^{0}$ 2). Este equipamento tinha capacidade de bombear $300 \mathrm{l} / \mathrm{h}$ (trezentos litros por hora), porém o sistema foi configurado para uma vazão de 4l/h (quatro litros por hora) para aumentar a eficiência e compatibilizar sua escala com um sistema real. A partir do volume total do sistema, de 250 litros úteis, e com a vazão configurada, temos que o TDH (tempo de detenção hidráulico) médio no sistema foi de até 64 horas, e considerando apenas as câmaras de filtragem, de até 33 horas (VON SPERLING, 2014). 
Avaliação de um equipamento protótipo para tratamento de águas cinzas com fins não potáveis

Com o protótipo montado e configurado, o mesmo foi abastecido com um litro e meio de água potável e foram adicionados $3 \mathrm{ml}$ de solução anticloro (tiossulfato de sódio em $100 \mathrm{~g} / \mathrm{L}$ ), com a finalidade de proporcionar um bom ambiente para o desenvolvimento das bactérias. Posteriormente inseriu-se $10 \mathrm{ml}$ da solução de concentrado de bactérias vivas, SpecialBlend®, acelerando a proliferação das bactérias, já que o produto possui milhões de colônias nesse volume. Deixou-se o sistema ligado, ciclando água potável apenas, durante uma semana.

Após esse período, fez-se a introdução de vinte litros de águas cinzas, sendo essa água coletada pelos autores do resíduo do banho e lavagem de roupas, que ficou circulando no protótipo pelo intervalo de 125 horas totais. Durante esse período foram coletadas cinco amostras de água mais uma amostra testemunha (retirada da água inicial diluída), que é a própria água cinza, para procederem-se as análises. As coletas foram realizadas nos intervalos de 3, 6, 72, 96 e 125 horas. Esses intervalos foram previamente selecionados de acordo com a expectativa da eficiência do protótipo somado à logística do laboratório onde ele estava instalado.

As amostras coletadas foram congeladas (exceto a coleta de água para teste de coliformes termotolerantes, que foi retirada ao final e diretamente enviada ao laboratório de análises) até o momento de iniciar os testes laboratoriais para a análise do IQA - Índice de Qualidade das Águas. 0 IQQA é determinado pela Agência Nacional de Águas e é composto por nove parâmetros em que cada um possui um peso dado em função da sua importância final na qualidade da água e curvas médias de variação dos parâmetros. 0 índice final é dado através de um produto ponderado desses parâmetros e é classificado em faixas que variam para cada Estado brasileiro, sendo: ótima $(80 \leq \mathrm{I} Q \mathrm{Q} \leq 100)$, boa $(52 \leq \mathrm{I} Q \mathrm{Q} \leq 79)$, razoável $(37 \leq \mathrm{I} Q \mathrm{~A} \leq 51)$, ruim $(20 \leq \mathrm{IQA} \leq 36)$ e péssima $(0 \leq \mathrm{IQA} \leq 19)$ (ANA, 2016). São esses parâmetros o pH, turbidez, sólidos totais, nitrogênio, oxigênio dissolvido, fósforo, coliformes termotolerantes, temperatura, e a demanda bioquímica de oxigênio (DB0). Nos testes incluiu-se ainda o parâmetro da demanda química de oxigênio (DQ0), por sua influência comparativa nos resultados.

Para a leitura do pH, turbidez, e oxigênio dissolvido utilizou-se de um "Phmetro", um "turbidímetro" e um "oxímetro", respectivamente, com resultados obtidos através de leitura direta. As medições do fósforo e do DQ0 foram realizadas em um espectrofotômetro, pelo método colorimétrico de Zuccari (1996). A DB0 foi realizada pelo Método Winkler (azida sódica) e 0xitop, no qual as amostras são colocadas em uma garrafa âmbar com quantidade suficiente de microorganismos e nutrientes a temperatura controlada de $201^{\circ} \mathrm{C}$, através de agitação 002 
presente na câmara de ar se dissolve no líquido. 0s microorganismos consomem este oxigênio dissolvido na amostra, liberando C02, que é absorvido pelos grânulos de $\mathrm{NaOH}$ presentes em um reservatório de borracha, gerando uma diferença de pressão na garrafa, que é medida pelo sensor 0xitop, esse teste é realizado durante 5 dias (BEM \& DOMBROSKI, 2017). 0 teste de nitrogênio foi realizado pelo método de Kjeldahl NKT, que consiste em digerir a amostra, com ácido sulfúrico, para converter nitrogênio orgânico em íon amônio. 0 sulfato de amônio resultante da digestão é aquecido com uma base, liberando amônia, esta é recolhida em uma solução ácida, e é determinada por colorimetria a quantidade de N-NH4+ (Yasuhara \& Nokihara, 2001). 0 teste de sólidos foi realizado através de pesagem simples, após o tratamento térmico das cápsulas a $900^{\circ} \mathrm{C}$ por duas horas.

0 parâmetro da temperatura não foi estudado visto que de acordo com SEMAD (2005), a mesma é uma constante, pois no Brasil a variação da temperatura de equilíbrio é próxima de zero. Também é importante lembrar que para realizar as análises a água foi aquecida até atingir a temperatura de $20^{\circ} \mathrm{C}$, devido à calibragem dos equipamentos.

\section{RESULTADOS E DISCUSSÃ0}

Os resultados obtidos a partir das análises realizadas com base nas amostras que foram colhidas, foram comparados com parâmetros de normas regulamentares aproximadas ao tema, notademente guiadas pela análise comparativa dos resultados previstos

\section{- Coliformes termotolerantes}

0 parâmetro dos coliformes termotolerantes foi medido na última amostra devido à necessidade de aquisição em laboratório externo. 0 resultado obtido foi de 4,5x10NMP/100mL. De acordo com a Lei $\mathrm{n}^{0} 2856$ (NITERÓI, 2011), deve-se obter ausência de coliformes termotolerates em 100mL, no entanto é importante ressaltar que a amostra coletada não foi clorada, justamente para que fosse possível identificar a presença ou não de coliformes sem o tratamento prévio. Pode-se afirmar que com tratamento simples de cloragem, todos os coliformes teriam sido eliminados. Resultado muito semelhante, obteve Valentina (2009), que em seu estudo sobre tratamento de água cinza para reuso registrou valores médios de 3,3 x10² NMP/100 mL para coliformes totais.

\section{- Oxigênio dissolvido}


Avaliação de um equipamento protótipo para tratamento de águas cinzas com fins não potáveis

0 oxigênio dissolvido garante a sobrevivência de todos os seres aquáticos e é consumido no processo de respiração e no sistema de decomposição da matéria orgânica, a qual é natural em ambientes aquáticos (LIMA, 2014).

De acordo com a Agência Nacional de Águas (Ana, 2016) águas poluídas por esgotos apresentam baixa concentração de oxigênio dissolvido, pois o mesmo é consumido no processo de decomposição da matéria orgânica. De acordo com as análises efetuadas (gráfico l) pode-se notar que na $1^{0}$ coleta obteve-se a leitura de $12,58 \mathrm{mg} / \mathrm{L}$ bem próximo ao valor da água testemunha que foi de $12,50 \mathrm{mg} / \mathrm{L}$. Já nas próximas coletas pôde-se perceber um aumento considerável, deste parâmetro, notadamente na $2^{\circ}$ e $5^{\circ}$ coleta, em que os resultados foram de 12,96 mg/L e 12,91 mg/L respectivamente. A queda da leitura da $3^{\circ}$ coleta, $12,72 \mathrm{mg} / \mathrm{L}$, pode ser explicada pelo consumo do oxigênio pelas bactérias, visto que em função da presença de carga de matéria orgânica, as colônias entraram em intenso desenvolvimento, consumindo oxigênio, até que $\log 0$ na sequência se equilibrando ao meio, ocorreu a normalização das taxas. De acordo com a NBR 13969/1997 para reuso agropecuário, na água de escoamento superficial ou por sistema de irrigação pontual, o oxigênio dissolvido mínimo deve estar acima de $2,0 \mathrm{mg} / \mathrm{L}$. A média do parâmetro oxigênio dissolvido obtida para as águas cinza tratadas foi de 12,81 mg/L, sendo que nem a amostra inicial tem uma taxa abaixo da permitida.

Para ocorrer a manutenção da vida aquática aeróbia exige-se níveis de oxigênio dissolvido maiores ou iguais 4,0 mg/L, uma faixa abaixo de 3,0 mg/L é considerada subletal, o que pode acarretar na asfixia de peixes e desequilíbrio na concentração de fitoplâncton (SNATURAL, 2011).

Gráfico 1. Resultados de oxigênio dissolvido nas respectivas coletas e média móvel (mg/L).

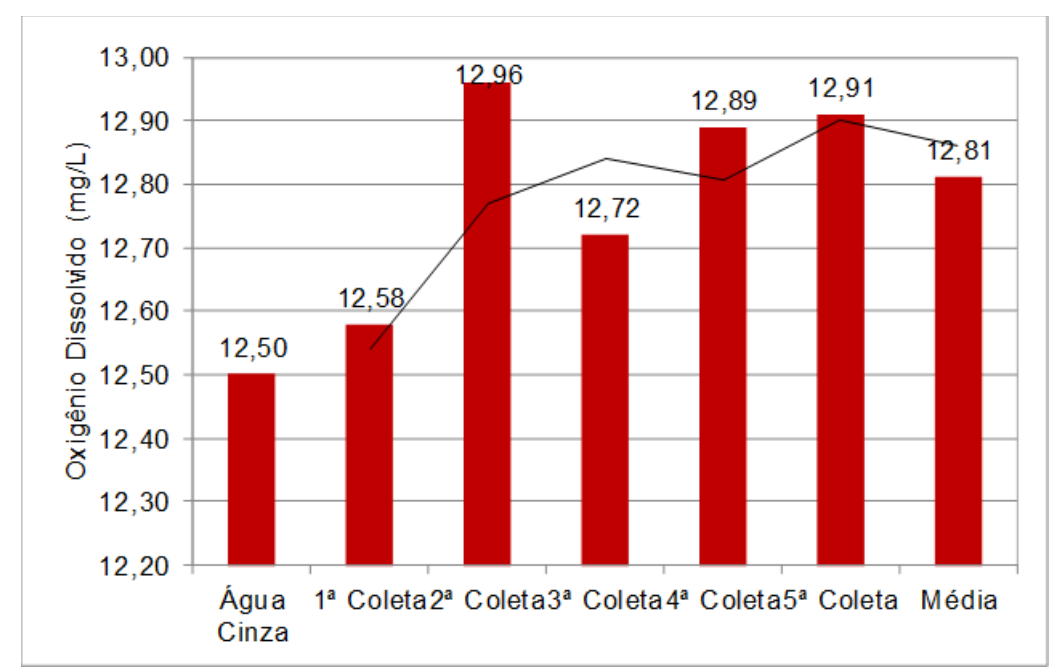

Fonte: Autores, 2016. 
- Demanda Bioquímica de 0xigênio (DB0) e Demanda Química de 0xigênio (DQ0)

Os parâmetros de DB0 e DQ0 avaliam o consumo ou a demanda de oxigênio necessário para estabilizar a matéria orgânica presente na amostra de água. A atividade respiratória das bactérias é um exemplo de estabilização da matéria orgânica (ERIKSSON et al., 2002). A relação entre os valores de DQ0 e DB0 indica a parcela de matéria orgânica que pode ser estabilizada por via biológica (BRASIL, 2014).

A DB0 representa a quantidade de oxigênio necessária para oxidar a matéria orgânica presente na água, através da decomposição microbiana aeróbia, e, analisando os valores encontrados (gráfico 2) observou-se que a amostra de água cinza continha 230,0 mg/L, que na primeira coleta reduziu-se em aproximadamente 48\%, chegando ao valor de $120 \mathrm{mg} / \mathrm{L}$, ou seja, poucas horas de tratamento geraram um bom resultado nesse parâmetro. A partir da $3^{\circ}$ coleta, o valor do DB0 apareceu com nulidade. 0 Manual do Sinduscon (SINDUSC0N, 2005) estabelece que para descarga de bacias sanitárias, lavagem de pisos, fins ornamentais (chafarizes, espelhos de água etc.) e lavagem de roupas e de veículos, deve-se obter uma DB0 $\leq 10 \mathrm{mg} / \mathrm{L}$.

Analisando os resultados quanto a DQ0 (gráfico 2) observou-se que o valor encontrado na água cinza coletada foi de 754,43 mg/L e que nas primeiras três horas de tratamento houve uma redução de aproximadamente $58 \%$. Na $2^{\circ}$ coleta foi possível perceber um pequeno aumento da taxa, ocasionado devido ao desenvolvimento dos microrganismos que consumiram o recurso, e, nas coletas seguintes, pode-se observar uma redução considerável e uniforme da DQ0. De acordo com a Proposta complementar à Resolução CONAMA n ${ }^{\mathrm{a}}$ 357/2005 (BRASIL, 2005), na comunidade europeia o limite para a demanda química de oxigênio (DQ0) não deve exceder a 125 mg/L, e de acordo com a NBR 13969/1997, o despejo de efluentes tratados nas galerias de águas pluviais deve conter DQ0 inferior a 150mg/L. Para os resultados, a média obtida foi de 199,32 mg/L, mas a partir da terceira coleta, notou-se que os resultados ficaram abaixo dos limites exigidos pelas duas normas, apontando a eficiência do tratamento, confirmada pelas repetições dos dados das últimas coletas.

Comparando os resultados obtidos entre os próprios parâmetros, percebeu-se que no início do tratamento da água cinza coletada, a demanda de oxigênio para oxidar a matéria orgânica é alta, o que resultou em valores elevados da DQO e DBO e valores reduzidos de oxigênio dissolvido. Com a ciclagem do efluente no protótipo, houve o aumento do oxigênio dissolvido e consequentemente a redução das demandas, $\log 0$ conclui-se que a decomposição do material orgânico foi satisfatória. 
Gráfico 2. Resultados da demanda bioquímica de oxigênio e da demanda química de oxigênio nas respectivas coletas $(\mathrm{mg} / \mathrm{L})$.

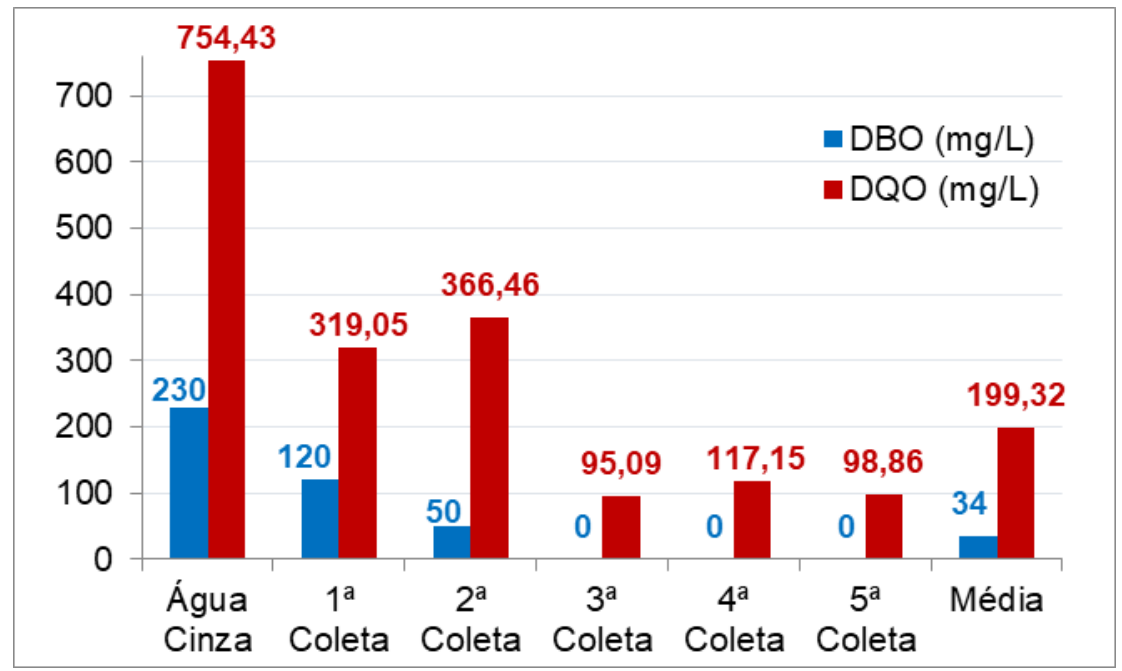

Fonte: Autores, 2016.

- Potencial hidrogeniônico

Quanto às análises de pH (gráfico 3) observou-se que a água cinza apresentou originalmente um pH alcalino. Já na $1^{0}$ coleta notou-se uma acidificação provavelmente pela degradação e decomposição da matéria orgânica, liberando composto nitrogenado que provoca a redução do pH. 0s resultados desse parâmetro foram praticamente constantes demonstrando que o sistema não altera o pH original, que é uma vantagem. A recomendação através da ANA (Ana, 2016) é que o pH se mantenha entre 6 e 9, e os resultados obtidos mantiveram uma média de 7,19, mostrando eficiência nesse quesito.

Os resultados obtidos nesse parâmetro vão de encontro com MERGULHÃO \& EMERY

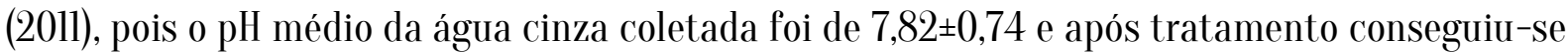
0 valor de 7,14 $\pm 0,24$. Ambos obtiveram uma pequena redução, porém atendeu-se os padrões de água de reuso da Alemanha e Japão e no Brasil ficou dentro da classe 1 de reuso que deve ficar com pH entre 6 e 8 segundo a NBR 13.969/97.

Gráfico 3. Resultados de pH nas respectivas coletas e média móvel. 


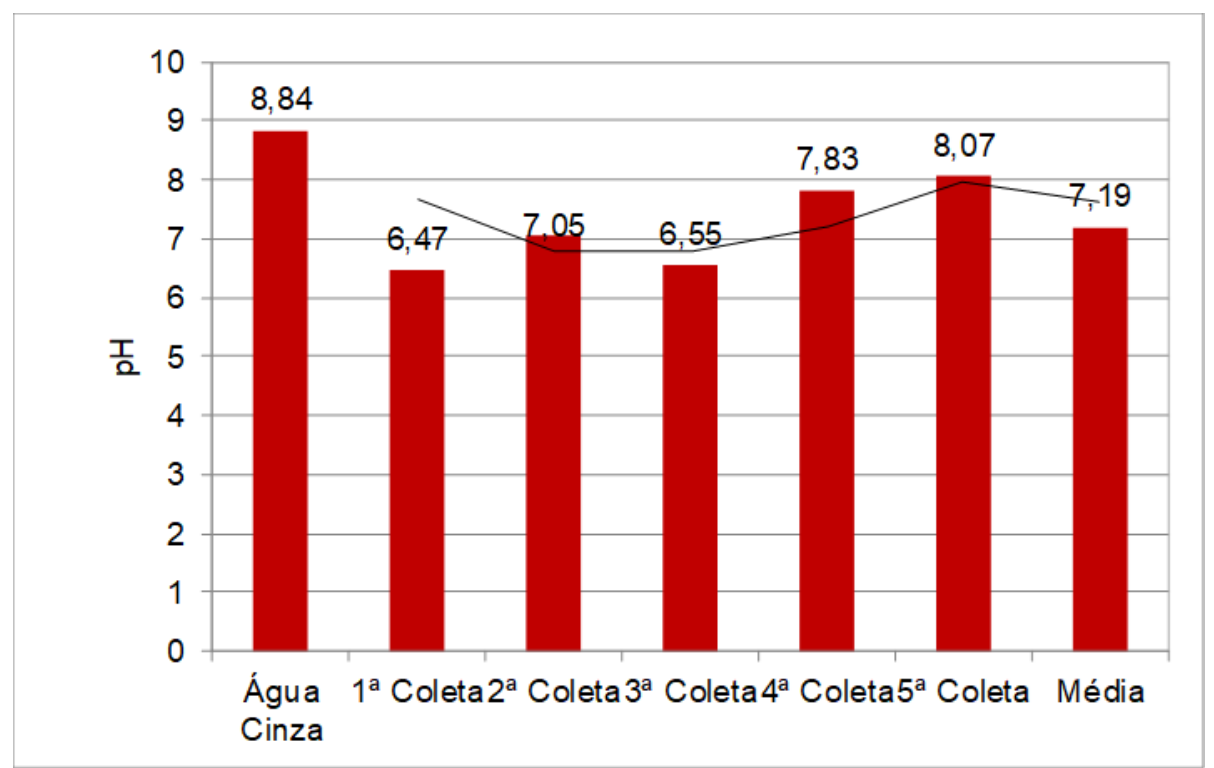

Fonte: Autores, 2016.

- Turbidez

0 teste de turbidez indica 0 grau de atenuação que um feixe de luz sofre ao atravessar a água. Analisando os resultados (Gráfico 4) percebeu-se que na amostra da água cinza o valor encontrado foi de zero, porém a água de testemunho estava bem turva, logo entendeu-se que o feixe de luz não passou pela amostra e, denotando que a amostra inicial ultrapassou a capacidade limite (superior) de leitura do equipamento, tamanha a turbidez que apresentará. Nas primeiras três horas de tratamento, quando foi realizada a primeira coleta, obteve-se uma redução e o valor encontrado foi de 82,90 UT. A Lei no 2856 (NITERÓI, 2011, art.3) apresenta que esse parâmetro deve ser inferior a 5UT, constatou-se que na $4^{\mathrm{a}}$ e $5^{\mathrm{a}}$ coleta esse valor foi atingido com 4,11 UT e 3,80 UT. Já o Manual do Sinduscon (SINDUSC0N, 2005) estabelece que para descarga de bacias sanitárias, lavagem de pisos, fins ornamentais (chafarizes, espelhos de água etc.) e lavagem de roupas e de veículos, deve-se obter uma turbidez $\leq 2$ UT. A média para esse parâmetro foi de 31,06 UT, valor considerado alto, porém é importante ressaltar uma tendência decrescente resultando em um tratamento eficiente quanto a turbidez.

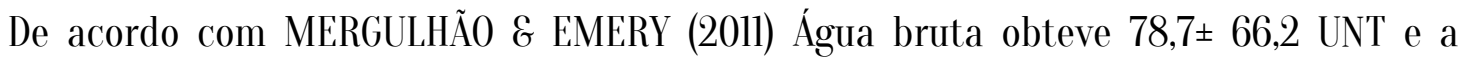
turbidez da água de reuso obteve uma média de 7,6ะ5,2 UNT. Já SACCON (2009) em seu estudo, obteve uma eficiência de $96 \%$ chegando a 0,8 a 12,2 UNT.

Gráfico 4. Resultados de turbidez nas respectivas coletas e média móvel (UT). 


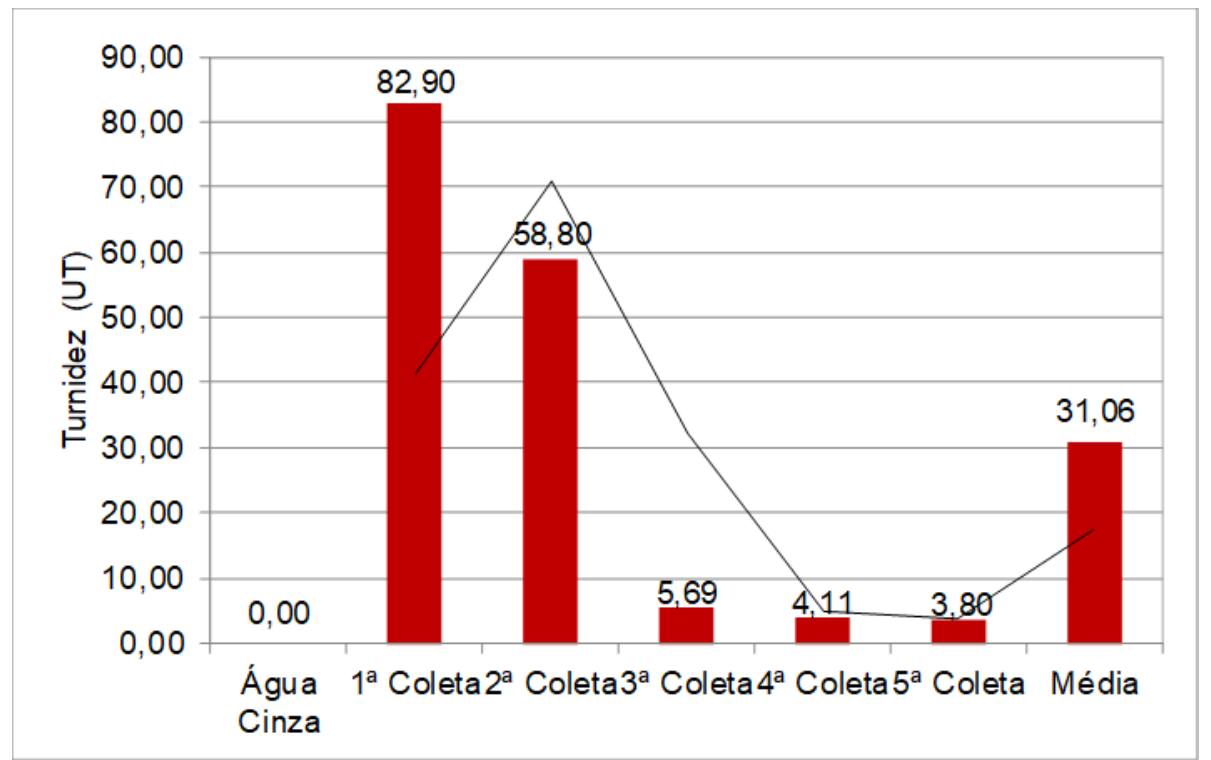

Fonte: Autores, 2016.

- Sólidos dissolvidos totais

Analisando os resultados apresentados (Gráfico 5) para o parâmetro dos sólidos dissolvidos totais (o equivalente a matéria que permanece após a evaporação, secagem ou calcinação de uma amostra de água), percebeu-se que nas primeiras três horas de tratamento, até 0 momento da realização da primeira coleta, houve uma redução de $61 \%$ em que os resultados passaram de 941,00 mg/L para 368,00 mg/L. Já percebendo uma eficiência visando o Manual do Sinduscon (SINDUSCON, 2005) que estabelece que para descarga de bacias sanitárias, lavagem de pisos, fins ornamentais (chafarizes, espelhos de água etc.) e lavagem de roupas e de veículos, deve-se obter SDT $\leq 500 \mathrm{mg} / \mathrm{L}$. As coletas seguintes denotaram essa tendência de redução, porém foi a partir da $5^{\circ}$ coleta que o valor previsto pela Lei $\mathrm{n}^{0} 2856$ (NITERÓI, 2011), em que os sólidos dissolvidos totais devem ser inferiores a 200,00 mg/L, foi atingido. A média do parâmetro foi de 271,00mg/L, mostrando eficiência do tratamento para esse parâmetro.

Comparando o parâmetro acima abordado, com o da turbidez, foi possível perceber uma correlação, visto que quanto mais partículas na água, menos límpida está será. Entendeuse que um comprova os resultados do outro, sendo observado que ambos tiveram resultados decrescentes, caracterizando uma água com aparência mais agradável do que a água cinza inicial.

Gráfico 5. Sólidos dissolvidos totais nas respectivas coletas e média móvel(mg/L). 


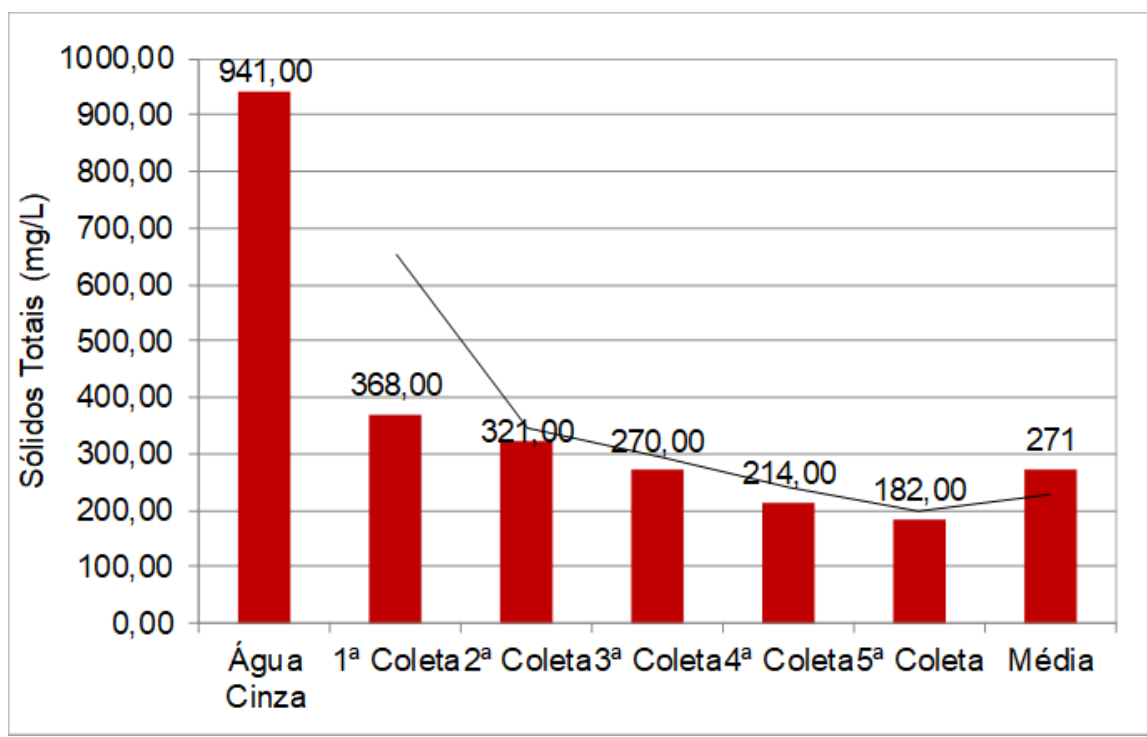

Fonte: Autores, 2016.

- $\quad$ Nitrato total e Fosfato total

De acordo Agência de Águas (ANA, 2016), os nitratos em altas concentrações são tóxicos e causam doenças até letais, como a chamada metahemoglobinemia infantil. 0 fósforo, assim como o nitrogênio, é um importante fator para os processos biológicos, pois em excesso causam a eutrofização das águas, uma modificação das características químicas, biológicas e físicas da mesma.

Utilizou-se como parâmetros comparativos a Resolução CONAMA Nº 357 (CONAMA, 2005) que apresenta os valores para água doce de classe 1. Segundo esta, o fosfato não deve ultrapassar o valor de $0,020 \mathrm{mg} / \mathrm{L}$ e 0 nitrato não deve ser maior que $3,7 \mathrm{mg} / \mathrm{L}$ para um pH menor que 7,5 ou $0,5 \mathrm{mg} / \mathrm{L}$ para uma pH maior que 8,5. Analisando esses dados (Gráfico 6), concluiu-se que 0 tratamento foi eficiente a partir da $3^{\mathrm{a}}$ coleta para o fósforo e da $4^{\mathrm{a}}$ coleta para o nitrogênio.

Gráfico 6. Resultados de nitrato total e fosfato total nas respectivas coletas (mg/L). 
Avaliação de um equipamento protótipo para tratamento de águas cinzas com fins não potáveis

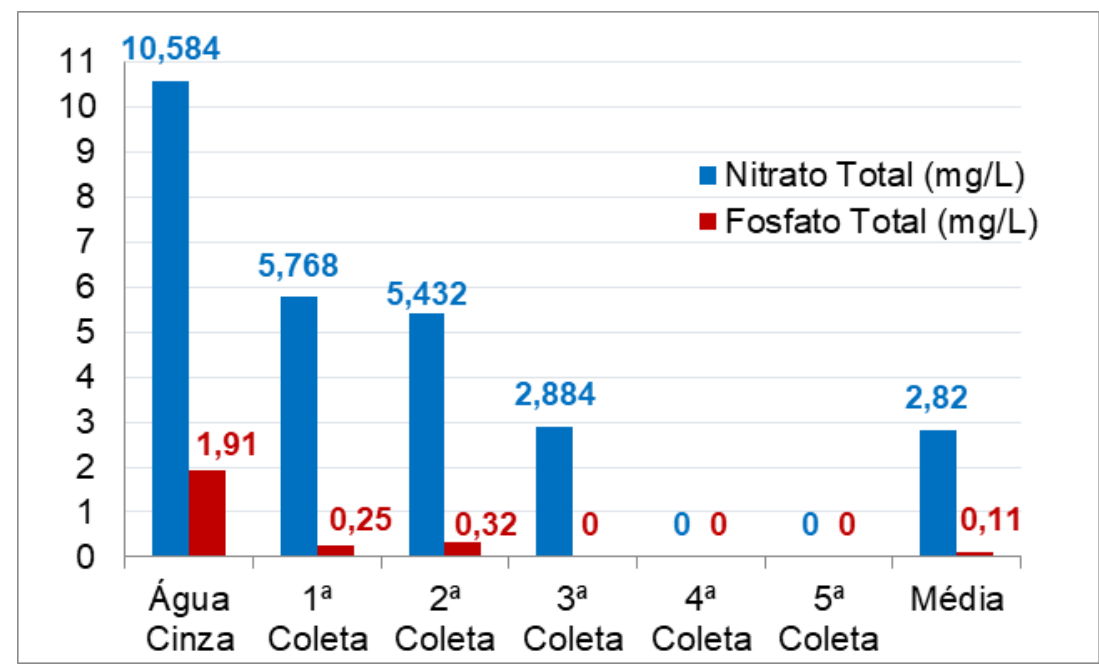

Fonte: Autores, 2016.

Comparando os resultados encontrados com Saccon (2009), temos que o autor ao estudar os parâmetros de fosfato total em tratamento de água cinza auferiu redução de $76 \%$ nas médias dos tratamentos, e chegou a $22,87 \mathrm{mg} / \mathrm{L}$ em resultado, bastante superior à média obtida no presente. Já MERGULHÃo \& EMERY (2011), relatam remoção média de 46\% para o nitrato total, considerada satisfatória para amostras de água cinza urbana - resultados de 3,3 $\mathrm{mg} / \mathrm{L}$, maiores ou menores que os encontrados no presente resultado.

Tabela 1. Resultados dos parâmetros analisados em todas as coletas.

\begin{tabular}{|c|c|c|c|c|c|c|c|c|}
\hline AMOSTRAS & Nitrato & Fosfato & DBO & DQO & $O D$ & $\mathrm{pH}$ & Turbidez & Sólidos Totais \\
\hline Água Cinza & 10,58 & 1,91 & 230,00 & 754,43 & 12,50 & 8,84 & 0,00 & 941,00 \\
\hline $1^{\text {a }}$ Coleta & 5,77 & 0,25 & 120,00 & 319,05 & 12,58 & 6,47 & 82,90 & 368,00 \\
\hline $2^{\text {a }}$ Coleta & 5,43 & 0,32 & 50,00 & 366,46 & 12,96 & 7,05 & 58,80 & 321,00 \\
\hline $3^{\text {a }}$ Coleta & 2,88 & 0,00 & 0,00 & 95,09 & 12,72 & 6,55 & 5,69 & 270,00 \\
\hline $4^{\mathrm{a}}$ Coleta & 0,00 & 0,00 & 0,00 & 117,15 & 12,89 & 7,83 & 4,11 & 214,00 \\
\hline $5^{\text {a Coleta }}$ & 0,00 & 0,00 & 0,00 & 98,86 & 12,91 & 8,07 & 3,80 & 182,00 \\
\hline Média & 4,11 & 0,41 & 66,67 & 291,84 & 12,76 & 7,47 & 25,88 & 382,67 \\
\hline Desvio Padrão & 3,15 & 0,50 & 72,22 & 188,14 & 0,16 & 0,78 & 29,98 & 186,11 \\
\hline $\mathrm{CV}$ & 76,62 & 120,70 & 108,33 & 64,47 & 1,25 & 10,42 & 115,82 & 48,64 \\
\hline
\end{tabular}

Unidades de medida: Nitrato total (m g/L); Fos fato total (m g/L); DBO (mg/L); DQO (m g/L); OD (m g/L); Turbidez (UT); Sólidos Totais ( $\mathrm{mg} / \mathrm{L}$ )

Fonte: Autores, 2018.

A heterogeneidade dos dados, notadas para todos os parâmetros analisados, exceto 0 de oxigênio dissolvido (0D), apresentados pela Tabela 1, demonstra tanto a dispersão absoluta quanto a relativa, na maior parte do tempo, muito elevada. Compreende-se que para o cenário analisado, intencionando apenas verificar sua dispersão, os dados demonstram distância 
relativa entre si, apropriadas ao tema (INF0RZAT0, 2008). As análises feitas, repetidas em tempos distintos da permanência no sistema, tendem a distanciar em qualidade, já que o tratamento tende a progressividade de eficiência a cada ciclo. Para os parâmetros mais homogêneos, era esperada a menor interferência das câmaras de filtragem, já que seus sistemas buscam dar permanência às características não tratadas pelos mesmos, o que notase mais presente tanto no oxigênio dissolvido (o sistema oxigena a água permanentemente pela queda hidráulica entre as câmaras), quanto para $0 \mathrm{pH}$, que tende à sua permanência por não interferência do sistema, enquanto houver equilíbrio da fauna de limpeza biológica.

- Cálculo do Índice de Qualidade das Águas

Em acordo com a análise de coliformes termotolerantes, o índice de qualidade da água foi calculado para a $5^{\text {a }}$ coleta, seguindo a metodologia de ANA (2016) e da SEMAD (2005).

Utilizou-se a fórmula $I Q A=\prod_{k=1}^{n} q_{i} w_{i}$, em que q i $=$ qualidade do parâmetro (resultado da análise); w i = peso correspondente ao parâmetro em função da sua importância para a conformação global da qualidade (número entre 0 e 1), conforme Tabela 2. Antes de serem multiplicados por cada peso, os parâmetros precisaram ser transformados devido às diferenças das unidades de medida, através das equações demonstradas por SEMAD (2005).

Tabela 2. Parâmetros de qualidade da água.

\begin{tabular}{lc} 
Parâmetros de qualidade da água & Peso (w) \\
\hline Oxígênio dissolvido & 0,17 \\
Coliformes termotolerantes & 0,15 \\
Potencial hidrogiônico - Ph & 0,12 \\
Demanda Bioquímio de Oxigênio -DBO & 0,10 \\
Temperatura da água & 0,10 \\
Nitrogênio Total & 0,10 \\
Fósforo total & 0,10 \\
Turbidez & 0,08 \\
Resíduo Total & 0,08
\end{tabular}

Fonte: ANA, 2016.

0 valor final encontrado, para as condições analisadas, foi de 62,10, que é considerado um índice de boa qualidade, conforme as mesmas fontes, para o Estado de Goiás.

\section{CONCLUSÃ0}


Avaliação de um equipamento protótipo para tratamento de águas cinzas com fins não potáveis

Para 0 reuso das águas cinzas é necessário realizar o tratamento dessas águas e adequá-las aos padrões de qualidade compatíveis aos usos para os quais estas se destinarão, visando a diminuição dos riscos a saúde pública, a maior aceitabilidade dos usuários e a viabilidade técnica e econômica dos empreendimentos.

Na caracterização da amostra inicial, sem tratamento, realizada nesta pesquisa, pôdese constatar concentrações elevadas para todos os fatores analisados do IQA, considerando também a DQO. Analisando-se comparativamente apenas, a água de entrada no sistema, as coletas a partir do terceiro ponto, e os padrões estabelecidos para águas de uso urbano, podemos notar que as saídas de água, de amostras únicas por coleta, apresentaram valores aceitáveis para os padrões estabelecidos, que mesmo não possuindo repetições de mesma coleta, confirmaram-se pelos dados das coletas subsequentes.

Com base no tratamento e nas condições descritas no trabalho pode-se afirmar que 0 IQA da água tratada foi mantido dentro de um padrão de qualidade para o Estado de Goiás, visto que seu valor ficou na ordem de 62,10, por sua vez considerado bom. Percebe-se que houve um tratamento eficiente do efluente, o que pode ser constatado ao observar uma diminuição na faixa de $50 \%$ na maioria dos parâmetros, nas primeiras horas. Para o pH e oxigênio dissolvido, obteve-se uma pequena variação, porém os resultados estão dentro da faixa aceitável de qualidade.

As análises de turbidez e de sólidos dissolvidos foram as que apresentaram maior eficácia, na terceira coleta obteve-se aproximadamente uma redução de $91 \%$ e $71 \%$, respectivamente. Os valores da DBO e da DQ0 também apresentaram uma evolução significativa, visto que os parâmetros têm uma acentuada diminuição, como por exemplo, obtiveram-se valores satisfatórios a partir da terceira amostra para o parâmetro da DBO.

\section{AGRADECIMENTOS}

Agradecemos à Deus e aos nossos Pais, pela vida, ao nosso orientador Prof. Autor, pela inestimável sabedoria e auxílio, ao Autor e ao Autor, que nos ajudaram na construção do protótipo, à Pontifícia Universidade Católica de Goiás pelos conhecimentos adquiridos e ao laboratório de Engenharia Ambiental dessa instituição pelas análises, aos amigos e todos que nos apoiaram fazendo com que os momentos de dificuldades fossem superados. 


\section{REFERÊNCIAS BIBLIOGRÁFICAS}

ABNT NBR 13.969. Tanques sépticos - Unidades de tratamento complementar e disposição final dos efluentes líquidos - Projeto, construção e operação. Rio de Janeiro. 1997.

ANA - Agência nacional de águas. Indicadores de qualidade - Índice de qualidade das águas (IQA). Portal da qualidade das águas. 2016. Disponível em: <http://portalpnqa.ana.gov.br/indicadoresindice-aguas.aspx>. Acesso em: 16 mai. 2016.

BARRETO, Douglas. Perfil do consumo residencial e usos finais da água. 2008. Mestrado. Instituto de Pesquisas Tecnológicas do Estado de São Paulo, 2008.

BEM, Carla Cristina; DOMBROSKI, Luiz Fernando. Manual de procedimentos laboratoriais integra-climasul aplicado ao monitoramento de parâmetros associados à qualidade da água em corpos aquáticos. Disponível em: https://docs.ufpr.br/ heloise.dhs/TH058/Manual\%20POPs_agua_LABEAM.pdf>. Acesso em: 16 out. 2017.

BRASIL. Resolução Conselho Nacional do Meio Ambiente no 357, de 17 de março de 2005 Dispõe sobre a classificação dos corpos de água e diretrizes ambientais para o seu enquadramento, bem como estabelece as condições e padrões de lançamento de efluentes, e dá outras providências. Diário Oficial da União, Brasília - DF, março de 2005.

BRASIL. Ministério da Saúde. Fundação Nacional de Saúde. Manual de controle da qualidade da água para técnicos que trabalham em ETAS. Brasília, 2014. 112 p.

ERIKSSON, E.; AUFFARTH, K.; MOGENS, H. LEDIN, A. Characteristics of grey wastewater. Urban Water. v. 4, n.1, p. 58-104, 2002.

FREITAS, Eduardo De. Água potável. Brasil Escola. Disponível em $<$ http://brasilescola.uol.com.br/geografia/agua-potavel.htm>. Acesso em 01 de maio de 2016.

GALIZIA, J E MATSUMURA, T. A água. 2 ed., Publifolha,2009.

GLEICK, Peter H, 1996. Recursos de água. Na Enciclopédia do Clima e Tempo, ed. Por Superlogo H. Schneider, Oxford University Press, Nova lorque, vol. 2, pág. 817-823. Disponível em: < https://water.usgs.gov/edu/watercycleportuguese.html>. Acesso em 27/05/2018.

HASTENREITER, Tainá Alves. Estudo de viabilidade técnica e econômica de implantação de um sistema de reuso de água cinza para fim não potável em edificação empresarial. Vitória. 2013.

INFORZATO, Nelson Fernando et al. Dispersão de Poluentes num sistema ar-água: Modelagem matemática, aproximação numérica e simulação computacional. 2008.

LIMA, M. Levantamento dos pontos críticos e aplicação de boas práticas de manejo na piscicultura. Carlos Eduardo Matiaze. Rondônia. 2014. 76 p.

MERGULHÃO, J.C.Z. EMERY R.D.B. Avaliação do Desempenho de Uma Estação de Tratamento de Águas Cinzas Visando o Reúso Não Potável. Trabalho de Conclusão de Curso (Graduação em Engenharia Ambiental) - Departamento de Engenharia Ambiental, Universidade Federal do Espírito Santo, Vitória, ES, 2011.

NITERÓI. Lei n. 2856 de 25 de julho de 2011 - Estende as obrigações da Lei no 2630, de 07 de janeiro de 2009, instituindo mecanismos de estímulo à instalação de sistema de coleta e reutilização de águas servidas em edificações públicas e privadas. Prefeitura Municipal de Niterói, 25 de julho de 2011. 
SACCON, S. Uso de Leitos Cultivados com Macrófitas no Estudo da Eficiência do Tratamento de Águas Cinzas. Trabalho de Conclusão de Curso (Graduação em Engenharia Ambiental) Departamento de Engenharia Ambiental, Faculdade Dinâmica de Cataratas, Foz do Iguaçu, Pr, 2009.

SEMAD. Secretaria de Estado do Meio Ambiente e Desenvolvimento Sustentável de Minas Gerais. Sistema de Cálculo da Qualidade da água (SCQA) - Estabelecimento das Equações do índice de Qualidade das Águas (IQA). 2005.

SINDUSCON-SP. Conservação e Reúso da água em Edificações. São Paulo, Prol Editora Gráfica, 2005.

SNATURAL. Uso de bio-filtros na criação de peixe (tilápia) em tanques. São Paulo. 2011. Disponível em: <http://www.snatural.com.br/Aquicultura-Producao-Intensiva.html>.

SPERLING, M.von Introdução à qualidade das águas e ao tratamento de esgotos. 4 ed. Belo Horizonte: Departamento de Engenharia Sanitária e Ambiental; Universidade Federal de Minas Gerais, 2014.

VALENTINA, R.S.D. Gerenciamento da Qualidade e da Quantidade de Água Cinza em Uma Edificação Residencial de Alto Padrão com Vistas ao Seu Reúso Não Potável. Dissertação (Mestrado em Engenharia Ambiental) - Programa de Pós-Graduação em Engenharia Ambiental, Universidade Federal do Espírito Santo, Vitória, ES, 2009.

VIEIRA, André de Ridder, et al., Cadernos de Educação Ambiental: Água para Vida, Água para Todos. Livro das águas. Brasília. WWF-Brasil, 2006.

YASUHARA T., NOKIHARA K. High-throughput analysis of total nitrogen content that replaces the classic Kjeldahl method. Journal of agricultural and food chemistry, v.49, p.4581-4583, 2001.

ZUCCARI, Maria Lúcia. A digestão pelo calor de diluição e a determinação da demanda química de oxigênio (DQO) em águas e efluentes. 1996. vii, 89 f. Teses (doutorado) - Universidade Estadual Paulista, Faculdade de Ciências Agronômicas, 1996. Disponível em: <http://hdl.handle.net/11449/101844>. Acesso em: 17 out. 2017. 